OPEN ACCESS

Edited by:

Yuji Morita,

Aichi Gakuin University, Japan

Reviewed by:

Bindu Sukumaran,

Duke NUS Graduate Medical School,

Singapore

Catherine M. Logue,

lowa State University, USA

*Correspondence:

Karen A. Krogfelt

kak@ssi.dk

Specialty section:

This article was submitted to

Antimicrobials, Resistance and

Chemotherapy,

a section of the journal

Frontiers in Microbiology

Received: 27 January 2017

Accepted: 15 March 2017

Published: 04 April 2017

Citation:

Jensen HD, Struve C, Christensen SB and Krogfelt KA (2017) Cranberry

Juice and Combinations of Its Organic

Acids Are Effective against

Experimental Urinary Tract Infection

Front. Microbiol. 8:542.

doi: 10.3389/fmicb.2017.00542

\section{Cranberry Juice and Combinations of Its Organic Acids Are Effective against Experimental Urinary Tract Infection}

\author{
Heidi D. Jensen ${ }^{1,2}$, Carsten Struve ${ }^{1}$, Søren B. Christensen ${ }^{2}$ and Karen A. Krogfelt ${ }^{1 *}$ \\ ${ }^{1}$ Department of Bacteria, Parasites and Fungi, Statens Serum Institut, Copenhagen, Denmark, ${ }^{2}$ Natural Products and \\ Peptides, University of Copenhagen, Copenhagen, Denmark
}

The antibacterial effect of cranberry juice and the organic acids therein on infection by uropathogenic Escherichia coli was studied in an experimental mouse model of urinary tract infection (UTI). Reduced bacterial counts were found in the bladder $(P<0.01)$ of mice drinking fresh cranberry juice. Commercially available cranberry juice cocktail also significantly reduced $(P<0.01)$ bacterial populations in the bladder, as did the hydrophilic fraction of cranberry juice $(P<0.05)$. Quinic, malic, shikimic, and citric acid, the preponderant organic acids in cranberry juice, were tested in combination and individually. The four organic acids also decreased bacterial levels in the bladder when administered together $(P<0.001)$, and so did the combination of malic plus citric acid $(P<0.01)$ and malic plus quinic acid $(P<0.05)$. The other tested combinations of the organic acids, and the acids administered singly, did not have any effect in the UTI model. Apparently, the antibacterial effect of the organic acids from cranberry juice on UTI can be obtained by administering a combination of malic acid and either citric or quinic acid. This study show for the first time that cranberry juice reduce $E$. coli colonization of the bladder in an experimental mouse model of urinary tract infection and that the organic acids are active agents.

Keywords: cranberry juice, urinary tract infection, antimicrobial agents, natural products, E. coli, animal model

\section{INTRODUCTION}

Urinary tract infection (UTI), most frequently caused by Escherichia coli, is one of the most common bacterial infections in humans (Foxman, 2014). Up to $40-50 \%$ of women will suffer from UTI at least once during their lifetime (Foxman, 2003). This high prevalence and the worrying rise in antibiotic resistance among uropathogens emphasize the need for new approaches for treating and preventing UTIs. For many years, cranberry juice has been used as a remedy to prevent and cure UTIs (Jepson et al., 2012; Wang et al., 2012). The beneficial effect of cranberry juice against UTI has been debated in the literature and clinical studies have shown conflicting results; however some studies have shown a protective effect of cranberry juice against UTI (Reviewed by Jepson et al., 2012; Wang et al., 2012; Blumberg et al., 2013; Vasileiou et al., 2013). Cranberry juice is known to inhibit cellular adherence of uropathogenic E. coli strains expressing P fimbriae in vitro (Ofek et al., 1991; Weiss et al., 1998). Cranberry proanthocyanidins trimers ( $\mathrm{M}_{\mathrm{W}}$ 8-900), were found to abolish in vitro adherence of P-fimbriated E. coli to cellular structures containing 
$\alpha$-Gal $(1 \rightarrow 4) \beta$-Gal binding sites similar to those on uroepithelial cells (Foo et al., 2000a,b). Urine from mice drinking cranberry juice instead of water had bacterial anti-adherence activity in vitro (Sobota, 1984). The same activity was observed in urine from mice given drinking water in which proanthocyanidins were dissolved (Howell et al., 2001). This could indicate that a bioactive cranberry proanthocyanidin metabolite was present in the urine preventing adhesion (Howell, 2002). A key characteristic of cranberry juice is the low $\mathrm{pH}$ of 2.5 (Hong and Wrolstad, 1986) as well as the unique blend of the organic acids, quinic, malic, shikimic, and citric acid (Jensen et al., 2002), with quinic acid being the most preponderant of the four. The concentration of quinic acid, and the ratio of the concentration of quinic acid to malic acid of $1.36 \pm 0.12$ are relatively constant (Hong and Wrolstad, 1986; Kuzminski, 1996; Jensen et al., 2002) and are used to calculate percentage of cranberry content in juice drinks and to assess cranberry juice authenticity (Kuzminski, 1996). Major sugars present are glucose and fructose at a glucose-fructose ratio of 3.55, which is unusual for a fruit juice (Kuzminski, 1996). Citric and malic acid are used as food preservatives, being capable of inhibiting a wide variety of microorganisms, including Gram-negative bacteria (Doores, 1993). In addition to acidification, citric acid also functions as a metal-chelating agent (Verhoff, 1986) and may possibly exert its antimicrobial activity by disruptive action on the outer membrane (Helander and Mattila-Sandholm, 2000). Quinic acid might be metabolized to hippuric acid, which is a strong antibacterial agent (Fellers et al., 1933). However, the active compounds responsible for the effect of cranberry juice in UTI has not yet been fully elucidated.

Here, we investigated the antibacterial effect of cranberry juice and the organic acids therein on UTI using a mouse model of long-term ascending urinary tract infection. We show that cranberry juice inhibits $E$. coli bladder colonization and that the organic acids are active agents.

\section{MATERIALS AND METHODS}

\section{Bacterial Strain and Preparation of Inoculum for Infection Studies}

E. coli C175-94, a clinical UTI isolate, was used for the infection studies. It belongs to serotype O8:K48:H9 and express type 1 fimbriae but not P fimbriae (Struve and Krogfelt, 1999). For infection studies, the bacteria were grown overnight at $37^{\circ} \mathrm{C}$ in static Luria broth (Statens Serum Insitut), centrifuged at $6,500 \mathrm{~g}$ for $10 \mathrm{~min}$ and the pellet resuspended in $\mathrm{PBS}$

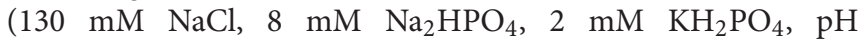
7.4; Statens Serum institut) to a concentration of $\sim 10^{10}$ $\mathrm{CFU} / \mathrm{ml}$.

\section{Mouse Model of Ascending UTI}

Six- to eight-week old, outbred albino female mice, Ssc:CF1, $30 \pm 2 \mathrm{~g}$ (SSI) were used. The mice were housed six to a cage and at all times provided free access to feed and water (control group) or treatment solutions. The model used was described in detail previously (Hvidberg et al., 2000). Anesthetized mice were inoculated transurethrally with $50 \mu \mathrm{l}$ bacterial suspension containing $\sim 5 \times 10^{8}$ CFUs using plastic catheters. The catheter was carefully inserted via the urethral orifice until it reached the top of the bladder and the bacterial suspension was slowly injected into the bladder. The catheter was immediately removed after inoculation and the mice subjected to no further manipulations until sacrifice. The mice were sacrificed 7 days after inoculation. For recovery of bacteria, bladders, and kidneys were aseptically collected in $0.9 \%$ saline and homogenized using a sterile grinder (IKA RW16 Basic), and serial dilutions were plated on selective media. All animal experiments were conducted under the auspices of the Danish Animal Experiments Inspectorate, the Danish Ministry of Justice.

\section{Treatment Studies}

After inoculation of the mice, the drinking water was substituted with cranberry juice or bioactive compounds in water for the rest of the experiment. A 7 day treatment period was chosen to obtain as long a treatment period as possible but at the same time avoiding the mice cleared the infection spontaneously. The control group and the treated groups all consisted of six mice in each trial. Most of the treatments were repeated two or more times in independent trials and the data were pooled and represented in Table 1. The reproducibility of the control group's infections rates in the independent trials were tested statistically with the Kruskal-Wallis test and found not to vary significantly.

\section{Cranberry Juice and Organic Acids Used for Treatment Studies}

Both commercially available and fresh cranberry juice were tested. Cranberry Juice Cocktail from Ocean Spray ${ }^{\circledR}$ is a $27 \%$ single-strength cranberry juice sold in grocery stores. It contains water, high fructose corn syrup, cranberry juice concentrate, and ascorbic acid. Fresh cranberry juice and the preparative isolation of the hydrophilic fraction of cranberry juice were prepared as previously described (Jensen et al., 2002). Frozen American cranberries (Vaccinium macrocarpon) from Northland Cranberries ${ }^{\circledR}$ were thawed at $5^{\circ} \mathrm{C}$ overnight and $1 \mathrm{~kg}$ of the berries blended with $700 \mathrm{ml}$ of deionized water for $5 \mathrm{~min}$ in a Waring Commercial Blendor. The pulp was centrifuged at $420 \mathrm{~g}$ for $15 \mathrm{~min}$ and the supernatant was filtered and adjusted to a volume of $1,000 \mathrm{ml}$ fresh cranberry juice. The hydrophilic fraction was made by applying $200 \mathrm{ml}$ cranberry juice on $20 \mathrm{~g}$ of RP-18 LiChroprep, $40-63 \mu \mathrm{m}$ silylated silica gel (Merck) in a $300 \times 20 \mathrm{~mm}$ column activated with methanol and washed with deionized water. The column was eluted with $300 \mathrm{ml}$ water and the eluates were pooled and evaporated in a vacuum evaporator at $40^{\circ} \mathrm{C}$ to the volume of the applied juice $(200 \mathrm{ml})$. The major constituents of the hydrophilic fraction were sugars (fructose and glucose), organic acids (quinic, malic, citric, and shikimic acid) and iridoid glycosides (monotropein and 6,7-dihydromonotropein; Jensen et al., 2002). Eluting the column with $96 \%$ ethanol $(500 \mathrm{ml})$ gave the ethanolic fraction. The eluate was concentrated to remove the ethanol in a rotavapor (Büchi Rotatvapor-R) at $40^{\circ} \mathrm{C}$ and kept at $-20^{\circ} \mathrm{C}$. Before use the residue was redissolved in deionized water 
TABLE 1 | Effect on median CFU per g bladder and urinary pH after administration of the specified agents in the drinking water.

\begin{tabular}{|c|c|c|c|c|c|c|}
\hline Treatment & Sample & $n$ & Median (CFU) & Interquartile ranges (CFU) & Fluid intake/mouse/day (ml \pm s.d.) & Urinary $\mathrm{pH}^{\mathrm{b}}$ \\
\hline Control group (Water) & Bladder & 47 & $5.4 \times 10^{4}$ & $\left(3.1 \times 10^{4}-1.8 \times 10^{5}\right)$ & $7.9 \pm 2.2$ & $6.5 \pm 0.2$ \\
\hline Cranberry juice cocktail & Bladder & 10 & $1.9 \times 10^{4 *}$ & $\left(1.5 \times 10^{4}-8.1 \times 10^{4}\right)$ & $4.2 \pm 0.3$ & - \\
\hline Fresh cranberry juice & Bladder & 35 & $2.9 \times 10^{4 \star \star}$ & $\left(1.6 \times 10^{4}-6.0 \times 10^{5}\right)$ & $3.0 \pm 0.5$ & $5.8 \pm 0.1$ \\
\hline Hydrophilic fraction & Bladder & 17 & $3.0 \times 10^{4 *}$ & $\left(6.3 \times 10^{3}-6.4 \times 10^{4}\right)$ & $3.9 \pm 0.3$ & - \\
\hline Mixture of organic acids ${ }^{a}$ & Bladder & 36 & $2.6 \times 10^{4 * \star \star}$ & $\left(1.0 \times 10^{4}-5.0 \times 10^{4}\right)$ & $3.1 \pm 0.7$ & $5.8 \pm 0.1$ \\
\hline
\end{tabular}

a Mixture of citric, malic, quinic, and shikimic acid in concentrations corresponding to the concentrations found in fresh cranberry juice.

${ }^{b}$ Control $n=14$, fresh cranberry juice $n=12$; organic acids $n=4$.

$P$-values indicated in the table: ${ }^{\star} P=0.01-0.05,{ }^{* \star} P=0.001-0.01,{ }^{* *} P<0.001$.

to volume corresponding to the applied juice $(500 \mathrm{ml})$. The ethanolic fraction of cranberry juice contained no sugars or organic acids but some not identified compounds, among them anthocyanins.

The organic acids used are commercially available (-)-quinic acid $(1 \beta, 3 \alpha, 4 \alpha, 5 \beta$-tetrahydroxycyclohexane carboxylic acid) (Aldrich), L-(-)-malic acid ( $S$-hydroxy-succinic acid) (Fluka), (-)-shikimic acid [(-)-3 $\alpha, 4 \alpha, 5 \beta$-trihy-droxycyclohexene-1-carboxylic acid] (Aldrich), and citric acid (2-hydroxy-1,2,3-propane-tricarboxylic acid) (Riedel-de Haën). A mixture of the four organic acids, in concentrations corresponding to those found in the hydrophilic fraction of cranberry juice, was tested as well as the acids separately or in mixtures two by two. The concentration of organic acids in the hydrophilic fraction of cranberry juice were $0.74 \%(\mathrm{w} / \mathrm{v})$ quinic, $0.53 \%(\mathrm{w} / \mathrm{v})$ malic, $0.03 \%(\mathrm{w} / \mathrm{v})$ shikimic, and $0.78 \%$ $(\mathrm{w} / \mathrm{v})$ citric acid, which gave a total concentration of $2.1 \%(\mathrm{w} / \mathrm{v})$. For the PBS experiment, PBS (130 mM NaCl, $8 \mathrm{mM} \mathrm{Na}_{2} \mathrm{HPO}_{4}$, $2 \mathrm{mM} \mathrm{KH}_{2} \mathrm{PO}_{4}$, pH 7.4; SSI) was $\mathrm{pH}$ adjusted to $\mathrm{pH} 3.0$ with $\mathrm{HCl}$.

\section{Statistical Methods}

The bacterial counts of infected bladders in each treatment group were compared to the control group using the Mann-Whitney $U$-test. $P<0.05$ were considered significant. All statistical calculations were performed by use of the GraphPad Prism software.

\section{RESULTS}

\section{Commercially Available and Fresh Cranberry Juice Significantly Reduce Bacterial Counts in Infected Bladders}

The mice in the control groups drinking only water were infected with a median of $5.4 \times 10^{4} \mathrm{CFU}$ per $\mathrm{g}$ bladder at sacrifice day 7 after inoculation (Table 1). Treatment with both commercially available Cranberry Juice Cocktail and fresh cranberry juice reduced the CFU in the bladder by 65\% $(P<0.01)$ and 47\% $(P<0.01)$, respectively (Table 1$)$. Also treatment with the hydrophilic fraction of cranberry juice decreased CFU in the bladder by $44 \%(P<0.05$; Table 1) whereas treatment with the ethanolic fraction of cranberry juice had no effect. Only very few mice had kidney infection and the bacterial counts were low prohibiting analysis of treatment effect in the kidneys (Results not shown).

\section{Combinations of the Most Prevalent Organic Acids in Cranberries Has an Effect against Bladder Infection}

The most prevalent organic acids from cranberry juice, citric-, malic-, quinic-, and shikimic acid were tested in concentrations corresponding to their respective concentration in fresh cranberry juice. The organic acids were tested as a mixture of four, as well as in combination two by two and individually. Treatment with a mixture of all four organic acids decreased the CFU in the bladder by $52 \%(P<0.001$; Table 1$)$. Treatment with a combination of malic- and citric acid or malicand quinic acid decreased the CFU in the bladder by $47 \%(P<$ $0.01)$ and $81 \%(P<0.05)$, respectively. Treatment with the other combinations of acids namely quinic plus shikimic acid; quinic plus citric acid; citric plus shikimic acid; and malic plus shikimic acid or each organic acid separately had no effect. Also treatment with quinic or citric acid in concentrations corresponding to the total concentration of the four acids did not have an effect.

\section{Intake of Fluid with Low pH Do Not Have an Effect on Bladder Infection}

To test if oral administration of a fluid with a low $\mathrm{pH}$ but without organic acids had any effect, we treated the mice with phosphate buffer $\mathrm{pH}$ 3. The treatment did not reduce the bacterial counts of infected bladders (data not shown).

\section{Mice Treated with Cranberry Juice or Solutions of Organic Acids Has Lower Fluid Intake and Lower Urinary pH}

Mice given cranberry juice or solutions of organic acids instead of drinking water drank less than the amount of water consumed by the control group. It could be speculated that the control group drank more due to the infection; however, the amount consumed corresponded with what has been previously described for non-infected mice (Bachmanov et al., 2002). Rather the lower amount consumed by treated mice may be due to the astringent and sour taste of cranberry juice and the organic 
acids. Importantly, no correlation between fluid intake and reduced CFU could be observed. Thus, addition of quinic acid to the drinking water afforded the lowest consumption of fluid (1.8 ml per day) but had no effect on the number of CFUs, whereas Cranberry Juice Cocktail was consumed in an amount close to pure water $(5.8$ and $6.5 \mathrm{ml} / \mathrm{day}$, respectively) and significantly reduced the bacterial count in infected bladders. Thus, the observed effect do not appear to be solely related to a more concentrated urine due to a low fluid intake.

The treatments were found to influence urinary $\mathrm{pH}$. Urinary $\mathrm{pH}$ was 6.5 in mice drinking water but was lowered to 5.8 in mice drinking cranberry juice or organic acids (Table $\mathbf{1}$ ).

\section{DISCUSSION}

The efficacy of treatment with cranberry juice or with constituents in cranberry juice was here, to the best of our knowledge, for the first time investigated in an experimental UTI mouse model. Our results revealed that oral administration to mice of commercially available Cranberry Juice Cocktail, fresh unsweetened cranberry juice, the hydrophilic fraction of cranberry juice, a combination of quinic, malic, citric, and shikimic acid, significantly reduced the number of viable organisms recovered from the bladder (Table 1). The mice consumed more commercially available Cranberry Juice Cocktail than fresh cranberry juice, perhaps due to the higher sugar content in the commercial drink and thereby more palatable taste. This may explain why the treatment effect of the commercial juice were higher than of the fresh juice.

Cranberry juice, have long been used for the prevention and treatment of UTIs. Some clinical studies have shown a prophylactic effect of cranberry juice against UTI in women although conclusions of different studies have been inconsistent (Reviewed by Jepson et al., 2012; Wang et al., 2012; Blumberg et al., 2013; Vasileiou et al., 2013).

Several in vitro studies have showed that cranberry juice possess antibacterial (Lee et al., 2000; Puupponen-Pimia et al., 2001; Nogueira et al., 2003), antifungal (Swartz and Medrek, 1968), antiviral (Konowalchuk and Speirs, 1978), and antiadhesive (Sobota, 1984; Schmidt and Sobota, 1988; Zafriri et al., 1989; Ofek et al., 1991; Ahuja et al., 1998; Weiss et al., 1998; Habash et al., 1999; Burger et al., 2000, 2002; Reid et al., 2001) properties.

We investigated the effect of oral administration of a mixture of quinic, malic, shikimic, and citric acid in the concentrations found in cranberry juice. The mixture of organic acids was comparable with cranberry juice in the effect of decreasing the number of CFU in the mouse bladder. The effect of treatment with the organic acids from cranberry juice on CFU in the bladder is interesting since the antibacterial effect of organic acids in cranberry juice have only been sparsely investigated. An effect of oral administered organic acids against diarrhea has been previously described (Tsiloyiannis et al., 2001). Organic acids, among them citric and malic acid were found to have a preventive effect on diarrhea in piglets. Post-weaning diarrhea of piglets is caused mainly by Enterotoxigenic E. coli (ETEC) strains (Tsiloyiannis et al., 2001). Groups were compared with regard to the appearance of clinical signs, mortality, weight gain, and feed conversion. All groups supplemented with organic acids had reduced incidence and severity of diarrhea, and performed significantly better than the negative group. The study indicates, that organic acids have an antibacterial and/or anti-adhesive effect on diarrhea causing ETEC strains in piglets (Tsiloyiannis et al., 2001). Our study indicates, that a similar effect on UPEC strains occur in the urinary tract.

In the experimental UTI model, the mice were inoculated directly in the bladder. Therefore, the antibacterial effect must occur at this site and the active components must be excreted in the urine. The organic acids tested in this experiment are likely to be excreted in the urine. Blatherwick and Long observed in 1923 that the excretion of both titratable, organic, and hippuric acid was elevated after the ingestion of cranberries (Blatherwick and Long, 1923). Quinic acid in cranberries might be metabolized to hippuric acid (Quick, 1931; Gonthier et al., 2003), which is a strong antibacterial agent (Fellers et al., 1933). Studies have shown that consuming large amounts of lemon, blackcurrant, and orange juice leads to a higher urinary excretion of citric acid (Wabner and Pak, 1993; Seltzer et al., 1996; Kessler et al., 2002). It is likely, that consumption of large amounts of malic acid would also lead to an increased urinary excretion of this acid.

We measured $\mathrm{pH}$ in the urine from infected mice drinking either water or cranberry juice and found a $\mathrm{pH}$ of $6.5 \pm 0.2$ and $5.8 \pm 0.1$, respectively. Our observation supports previous studies, which reported that cranberry juice functions as a urinary acidifier even in moderate amounts (Blatherwick, 1914; Blatherwick and Long, 1923; Bodel et al., 1959; Kahn et al., 1967; Light et al., 1973; Kinney and Blount, 1979; Schultz, 1984; Jackson and Hicks, 1997; Kessler et al., 2002).

Previous studies have shown that proanthycyanidins in cranberry juice have anti-adhesive effect against P-fimbriated E. coli (Foo et al., 2000a,b; Howell et al., 2001). Our study revealed that another antibacterial factor from cranberry juice involved in reducing UTI in a mouse model is the organic acids. The E. coli isolate used in the present study did not possess $\mathrm{P}$ fimbriae which may explain why the effect of cranberry juice and the combinations of organic acids were comparable. It could be speculated that a relatively higher effect of cranberry juice would be observed against urinary tract infection caused by a P-fimbriated E. coli strain. This should be investigated in future studies.

This study is to the best of our knowledge, the first to provide evidence of an antibacterial effect of consumption of cranberry juice and combinations of its organic acids by use of a mouse model of urinary tract infection. The active treatments reduced bacterial counts in the bladder but did not cure the infection, indicating that cranberry juice is not a definite treatment but it may promote clearance of the infection for instance in combination with antibiotics. Future studies designed 
at investigating the effect of organic acids from cranberries in human UTIs could facilitate the development of a functional food or drink containing these organic acids.

\section{AUTHOR CONTRIBUTIONS}

KK obtained the funding for the project. HJ, SC, and KK designed the study. HJ performed the experimental work. All

\section{REFERENCES}

Ahuja, S., Kaack, B., and Roberts, J. (1998). Loss of fimbrial adhesion with the addition of Vaccinum macrocarpon to the growth medium of P-fimbriated Escherichia coli. J. Urol. 159, 559-562. doi: 10.1016/S0022-5347(01)63983-1

Bachmanov, A. A., Reed, D. R., Beauchamp, G. K., and Tordoff, M. G. (2002). Food intake, water intake, and drinking sprout side preference of 28 mouse strains. Behav. Genet. 32, 435-443. doi: 10.1023/A:1020884312053

Blatherwick, N. R. (1914). The specific role of foods in relation to the composition of the urine. Arch. Intern. Med. 2, 409-450. doi: 10.1001/archinte.1914.00070150122008

Blatherwick, N. R., and Long, M. L. (1923). The increased acidity produced by eating prunes and cranberries. J. Biol. Chem. 57, 815-818.

Blumberg, J. B., Camesano, T. A., Cassidy, A., Kris-Etherton, P., Howell, A., Manach, C., et al. (2013). Cranberries and their bioactive constituents in human health. Adv. Nutr. 4, 618-32. doi: 10.3945/an.113.004473

Bodel, P. T., Cotran, R., and Kass, E. H. (1959). Cranberry juice and the antibacterial action of hippuric acid. J. Lab. Clin. Med. 54, 881-888.

Burger, O., Ofek, I., Tabak, M., Weiss, E. I., Sharon, N., and Neeman, I. (2000). A high molecular mass constituent of cranberry juice inhibits Helicobacter pylori adhesion to human gastric mucus. FEMS Immunol. Med. Microbiol 29, 295-301. doi: 10.1111/j.1574-695X.2000.tb01537.x

Burger, O., Weiss, E., Sharon, N., Tabak, M., Neeman, I., and Ofek, I. (2002). Inhibition of Helicobacter pylori adhesion to human gastric mucus by a highmolecular-weight constituent of cranberry juice. Crit. Rev. Food Sci. Nutr. 42, 279-284. doi: 10.1080/10408390209351916

Doores, S. (1993). "Organic acids," in Antimicrobials in Foods, eds P. M. Davidson and A. L. Branen (New York, NY: Marcel Dekker), 95-136.

Fellers, C. R., Redmon, B. C., and Parrott, E. M. (1933). Effect of cranberries on urinary acidity and blood alkali reserve. J. Nutr. 6, 455-463.

Foo, L. Y., Lu, Y., Howell, A. B., and Vorsa, N. (2000a). A-Type proanthocyanidin trimers from cranberry that inhibit adherence of uropathogenic P-fimbriated Escherichia coli. J. Nat. Prod. 63, 1225-1228. doi: 10.1021/np000128u

Foo, L. Y., Lu, Y., Howell, A. B., and Vorsa, N. (2000b). The structure of cranberry proanthocyanidins which inhibit adherence of uropathogenic P-fimbriated Escherichia coli in vitro. Phytochemistry 54, 173-181. doi: 10.1016/S0031-9422(99)00573-7

Foxman, B. (2003). Epidemiology of urinary tract infections: incidence, morbidity, and economic costs. Dis. Mon. 49, 53-70. doi: 10.1067/mda.2003.7

Foxman, B. (2014). Urinary tract infection syndromes: occurrence, recurrence, bacteriology, risk factors, and disease burden. Infect. Dis. Clin. North. Am. 28, 1-13. doi: 10.1016/j.idc.2013.09.003

Gonthier, M. P., Verny, M. A., Besson, C., Rémésy, C., and Scalbert, A. (2003). Chlorogenic acid bioavailability largely depends on its metabolism by the gut microflora in rats. J. Nutr. 133, 1853-1859.

Habash, M. B., Van der Mei, H. C., Busscher, H. J., and Reid, G. (1999). The effect of water, ascorbic acid, and cranberry derived supplementation on human urine and uropathogen adhesion to silicone rubber. Can. J. Microbiol. 45, 691-694. doi: 10.1139/w99-065

Helander, I. M., and Mattila-Sandholm, T. (2000). Fluorometric assessment of gram-negative bacterial permeabilization. J. Appl. Microbiol. 88, 213-219. doi: 10.1046/j.1365-2672.2000.00971.x

Hong, V., and Wrolstad, R. E. (1986). Cranberry juice composition. J. Assoc. Off. Anal. Chem. 69, 199-207. authors participated in the interpretation of the research data and contributed to the writing of the manuscript.

\section{FUNDING}

This work was supported by grant 9800989 from The Danish Medical Research Council to KK.

Howell, A. B. (2002). Cranberry proanthocyanidins and the maintenance of urinary tract health. Crit. Rev. Food Sci. Nutr. 42, 273-278. doi: $10.1080 / 10408390209351915$

Howell, A. B., Leahy, M. M., Kurowska, E., and Guthrie, N. (2001). In vivo evidence that cranberry proanthocyandins inhibit adherence of P-fimbriated E. coli bacteria to uroepithelial cells. Fed. Am. Soc. Exp. Biol. J. 15:A284.

Hvidberg, H., Struve, C., Krogfelt, K. A., Christensen, N., Rasmussen, S. N., and Frimodt-MØller, N. (2000). Development of a long-term ascending urinary tract infection mouse model for antibiotic treatment studies. Antimicrob. Agents Chemother. 44, 156-163. doi: 10.1128/AAC.44.1.156-163.2000

Jackson, B., and Hicks, L. E. (1997). Effect of cranberry juice on urinary $\mathrm{pH}$ in older adults. Home Healthc. Nurse 15, 198-202. doi: 10.1097/00004045-199703000-00007

Jensen, H. D., Krogfelt, K. A., Cornett, C., Hansen, S. H., and Christensen, S. B. (2002). Hydrophilic carboxylic acids and iridoid glycosides in the juice of American and European cranberries (Vaccinium macrocarpon and $V$. oxycoccos), lingonberries (V. vitis-idaea), and blueberries (V. myrtillus). J. Agric. Food Chem. 50, 6871-6874. doi: 10.1021/jf0205110

Jepson, R. G., Williams, G., and Craig, J. C. (2012). Cranberries for preventing urinary tract infections. Cochrane Database Syst. Rev. 10:CD001321. doi: 10.1002/14651858.CD001321.pub5

Kahn, H. D., Panariello, V. A., Saeli, J., Sampson, J. R., and Schwartz, E. (1967). Effect of cranberry juice on urine. J. Am. Diet. Assoc. 51, 251-254.

Kessler, T., Jansen, B., and Hesse, A. (2002). Effect of blackcurrant-, cranberry- and plum juice consumption on risk factors associated with kidney stone formation. Eur. J. Clin. Nutr. 56, 1020-1023. doi: 10.1038/sj.ejcn.1601442

Kinney, A. B., and Blount, M. (1979). Effect of cranberry juice on urinary pH. Nurs. Res. 28, 287-290. doi: 10.1097/00006199-197909000-00012

Konowalchuk, J., and Speirs, J. I. (1978). Antiviral effect of commercial juices and beverages. Appl. Environ. Microbiol. 35, 1219-1220.

Kuzminski, L. N. (1996). Cranberry juice and urinary tract infections: is there a beneficial relationship? Nutr. Rev. 54, S87-S90. doi: 10.1111/j.1753-4887.1996.tb03824.x

Lee, Y. L., Owens, J., Thrupp, L., and Cesario, T. C. (2000). Does cranberry juice have antibacterial activity? JAMA 283:1691. doi: 10.1001/jama.283.13.1691

Light, I., Gursel, E., and Zinnser, H. H. (1973). Urinary ionized calcium in urolithiasis. Effect of cranberry juice. Urology 1, 67-70. doi: 10.1016/0090-4295(73)90117-9

Nogueira, M. C., Oyarzábal, O. A., and Gombas, D. E. (2003). Inactivation of Escherichia coli O157:H7, Listeria monocytogenes, and Salmonella in cranberry, lemon, and lime juice concentrates. J. Food Prot. 66, 1637-1641. doi: 10.4315/0362-028X-66.9.1637

Ofek, I., Goldhar, J., Zafriri, D., Lis, H., Adar, R., and Sharon, N. (1991). AntiEscherichia coli adhesin activity of cranberry and blueberry juices. N.Engl. J. Med. 324:1599. doi: 10.1056/NEJM199105303242214

Puupponen-Pimiä, R., Nohynek, L., Meier, C., Kähkönen, M., Heinonen, M. Hopia, A., et al. (2001). Antimicrobial properties of phenolic compounds from berries. J. Appl. Microbiol. 90, 494-507. doi: 10.1046/j.1365-2672.2001.01271.x

Quick, A. J. (1931). The conjugation of benzoic acid in man. J. Biol. Chem. 92, 65-85.

Reid, G., Hsiehl, J., Potter, P., Mighton, J., Lam, D., Warren, D., et al. (2001). Cranberry juice consumption may reduce biofilms on uroepithelial cells: pilot study in spinal cord injured patients. Spinal Cord. 39, 26-30. doi: 10.1038/sj.sc.3101099 
Schmidt, D. R., and Sobota, A. E. (1988). An examination of the anti-adherence activity of cranberry juice on urinary and nonurinary bacterial isolates. Microbios 55, 173-181.

Schultz, A. (1984). Efficacy of cranberry juice and ascorbic acid in acidifying the urine in multiple sclerosis subjects. J. Community Health Nurs. 1, 159-169. doi: 10.1207/s15327655jchn0103_5

Seltzer, M. A., Low, R. K., McDonald, M., Shami, G. S., and Stoller, M. L. (1996). Dietary manipulation with lemonade to treat hypocitraturic calcium nephrolithiasis. J. Urol. 156, 907-909. doi: 10.1016/S0022-5347(01)65659-3

Sobota, A. E. (1984). Inhibition of bacterial adherence by cranberry juice: potential use for the treatment of urinary tract infections. J. Urol. 131, 1013-1016.

Struve, C., and Krogfelt, K. A. (1999). In vivo detection of Escherichia coli type 1 fimbrial expression and phase variation during experimental urinary tract infection. Microbiology 145, 2683-2690. doi: 10.1099/00221287-145-1 $0-2683$

Swartz, J. H., and, Medrek, T. F. (1968). Antifungal properties of cranberry juice. Appl. Microbiol. 16, 1524-1527.

Tsiloyiannis, V. K., Kyriakis, S. C., Vlemmas, J., and Sarris, K. (2001). The effect of organic acids on the control of porcine post-weaning diarrhoea. Res. Vet. Sci. 70, 287-293. doi: 10.1053/rvsc.2001.0476

Vasileiou, I., Katsargyris, A., Theocharis, S., and Giaginis, C. (2013). Current clinical status on the preventive effects of cranberry consumption against urinary tract infections. Nutr. Res. 33, 595-607. doi: 10.1016/j.nutres.2013.05.018

Verhoff, F. H. (1986). "Citric acid," in Ullmann's Encyclopedia of Industrial Chemistry, ed W. Gerhartz (Weinheim: VCH), 103-108.
Wabner, C. L., and Pak, C. Y. (1993). Effect of orange juice consumption on urinary stone risk factors. J. Urol. 149, 1405-1408.

Wang, C. H., Fang, C. C., Chen, N. C., Liu, S. S., Yu, P. H., Wu, T. Y., et al. (2012). Cranberry-containing products for prevention of urinary tract infections in susceptible populations: a systematic review and metaanalysis of randomized controlled trials. Arch. Intern. Med. 172, 988-996. doi: 10.1001/archinternmed.2012.3004

Weiss, E. I., Lev-Dor, R., Kashamn, Y., Goldhar, J., Sharon, N., and Ofek, I. (1998). Inhibiting interspecies coaggregation of plaque bacteria with a cranberry juice constituent. J. Am. Dent. Assoc. 129, 1719-1723. doi: 10.14219/jada.archive.1998.0141

Zafriri, D., Ofek, I., Adar, R., Pocino, M., and Sharon, N. (1989). Inhibitory activity of cranberry juice on adherence of type 1 and type $\mathrm{P}$ fimbriated Escherichia coli to eucaryotic cells. Antimicrob. Agents. Chemother. 33, 92-98. doi: 10.1128/aac.33.1.92

Conflict of Interest Statement: The authors declare that the research was conducted in the absence of any commercial or financial relationships that could be construed as a potential conflict of interest.

Copyright (c) 2017 Jensen, Struve, Christensen and Krogfelt. This is an open-access article distributed under the terms of the Creative Commons Attribution License (CC $B Y)$. The use, distribution or reproduction in other forums is permitted, provided the original author(s) or licensor are credited and that the original publication in this journal is cited, in accordance with accepted academic practice. No use, distribution or reproduction is permitted which does not comply with these terms. 